\title{
TRAJETÓRIAS REPRODUTIVAS FEMININAS E PRODUÇÃO DO CUIDADO EM SAÚDE ORIENTADO ÀS GESTANTES NA CIDADE DE SÃO LEOPOLDO/RS: UM OLHAR INTERSECCIONAL
}

\section{Carolina Pereira Montiel' \\ Laura Cecilia López ${ }^{2}$}

Resumo: Analisaram-se trajetórias reprodutivas de mulheres moradoras de bairro periférico de São Leopoldo (RS). Reflete-se sobre como dinâmicas de gênero, classe, raça e idade se interseccionam nessas trajetórias e na produção de cuidado. Foi uma pesquisa qualitativa sobre experiências de gestação de usuárias do pré-natal de uma Unidade de Saúde da Família. Os resultados mostraram trajetórias reprodutivas diferentes entre as mulheres, sendo que as violências e negligências apareceram mais acentuadas sobre os corpos femininos negros. Referente ao cuidado, aspectos reguladores (re)produzem certos ideais de maternidade e engajamentos nas realidades das mulheres, com efeitos em sua busca por autonomia reprodutiva.

Palavras-chave: Trajetórias reprodutivas; assistência pré-natal; interseccionalidade.

\begin{abstract}
We analyze the reproductive trajectories of women living in a peripheral neighborhood of São Leopoldo (RS) and reflect on how gender, class, race and age dynamics intersect with these trajectories as well as with the production of care. This qualitative research concerned the gestational experience of prenatal users of a Family Health Unit. The results showed reproductive trajectories with differences among women, with violence and neglect being more pronounced on black women. Regarding the production of care, we note regulatory aspects that reproduce certain ideals of motherhood, but also spaces of engagement in the realities of women, which affects their search for reproductive autonomy.
\end{abstract}

Keywords: Reproductive trajectories; prenatal care; intersectionality.

Mestra em Saúde Coletiva, Universidade do Vale do Rio dos Sinos, Brasil. E-mail: carolpmontiel@gmail.com. Orcid: 0000-0002-7034-9799

2 Doutora em Antropologia, pela Universidade Federal do Rio Grande do Sul, Brasil. Professora dos Programa de Pós-Graduação em Saúde Coletiva e em Ciências Sociais, Unisinos, Brasil. E-mail: lauracl1975@gmail.com. Orcid: 0000-0002-2454-063X 


\section{Introdução}

Ao pensar na ampliação do pré-natal como dispositivo sanitário garantido pelo Sistema Único de Saúde (SUS) no Brasil, chama atenção o fato de que as estatísticas atestam um aumento de acesso a esses serviços. Do ponto de vista epidemiológico, o estudo "Nascer no Brasil" mostrou que a cobertura no país é praticamente universal, com valores elevados em todas as regiões e entre mulheres com diferentes características demográficas, sociais e reprodutivas. Porém, a adequação dessa assistência ainda é baixa. Evidencia-se a relação entre menor acesso/menor qualidade e desigualdades persistentes no país, mostrando situações de vulnerabilidade entre mulheres indígenas e pretas, aquelas com menor escolaridade, com maior número de gestações e residentes nas regiões Norte e Nordeste (VIELLAS et al., 2014).

Em artigo relacionado ao mesmo estudo, Leal et al. (2017) analisam as iniquidades na atenção pré-natal e parto de acordo com a raça/cor das mulheres. Foram verificados piores indicadores entre as mulheres pretas e pardas, em comparação às brancas, sendo as primeiras mais suscetiveis a receber assistência pré-natal inadequada. Isso se expressa em menor número de consultas e exames, em precarização no vínculo à maternidade para o parto e no acesso a orientações, o que provoca baixa garantia de direitos como parturiente.

Entretanto poucos trabalhos se dedicaram à análise das mudanças nas formas de regulação e de subjetivação que a expansão desse dispositivo sanitário produz nos corpos grávidos. $\bigcirc$ estudo de Robles (2015) analisa as relações entre mulheres jovens de camadas populares usuárias dos serviços de saúde pública e os profissionais de saúde na construção de experiências da gravidez nas cidades de Recife e do Rio de Janeiro. A autora destaca a transmissão de normas específicas para o cumprimento do papel materno entre as mulheres jovens e a maneira como "os atendimentos do pré-natal têm se convertido em um dispositivo de regulação não somente de comportamentos e práticas corporais ligadas ao 'cuidado de si' e do 'outro a vir', mas também das relações de parentalidade" (ROBLES, 2015, p. 190).

Com o intuito de ampliar o olhar para as dinâmicas sociais que envolvem a saúde reprodutiva (para além da assistência pré-natal), questionamos como e em que medida a produção de cuidado com a gestação abarca (e tem efeitos sobre) as trajetórias reprodutivas de mulheres, cujas vidas estão atravessadas por várias assimetrias. Analisamos dados de uma pesquisa qualitativa que avaliou as experiências de gestação de usuárias de serviços de saúde na rede pública de São Leopoldo (RS), especialmente em uma unidade de saúde da família (USF), 
tanto a partir da observação etnográfica das interações entre trabalhadoras da saúde e usuárias quanto do aprofundamento das narrativas das gestantes.

Entendemos as trajetórias reprodutivas a partir de uma abordagem de gênero no sul global, conforme Connell (2016), que entende o gênero como uma estrutura de relações sociais que entrelaça corpos sexuais posicionados na história, sendo que o exercício da reprodução e da sexualidade é constitutivo e constituinte das relações de poder. Como categoria analítica, o gênero nos serve para indagar na organização das relações sociais e na produção de assimetrias envolvendo homens e mulheres (CONNELL, 2016). Consideramos a intersecção do gênero com outras assimetrias: de classe, com a concentração de renda em um grupo reduzido e uma enorme desigualdade no acesso a bens e serviços de grande parte da população brasileira (MATTAR; DINIZ, 2012); e raciais, ao entender raça como dispositivo de poder que perpetua o racismo e as assimetrias entre brancos e negros (LÓPEZ, 2012). Essas assimetrias constituem e potencializam hierarquias reprodutivas, sendo que "algumas maternidades são mais ou menos legítimas e aceitas socialmente do que outras - impactando o exercício de direitos humanos pelas mulheres" (MATTAR; DINIZ, 2012, p. 108).

Em relação à produção de cuidado em saúde, entendemos que constitui um "trabalho vivo em ato", que acontece em uma dinâmica relacional e instituinte, no encontro de sujeitos no próprio processo de trabalho (MERHY, 2013). No contexto de uma USF, pode-se apontar que o foco do cuidado na reprodução ou na saúde materno-infantil acompanhou a história da Estratégia/Programa e que a construção da ideia de família se sobrepõe à de gênero. Ao analisar essa construção, Scott (2011) ressalta que as políticas públicas que priorizam a "família" e, particularmente, as que envolvem assistência à saúde, assumem, muitas vezes, uma noção de família vinculada a papéis de sexo naturalizados, sendo instaurada uma "moral familiar" idealizada pelos profissionais da saúde, mas que na prática não corresponde aos arranjos diversos das pessoas atendidas. Esta noção naturalizada esconde relações de poder e desigualdade, enquanto uma perspectiva analítica de gênero (e suas intersecções) as abordaria explicitamente, tornando-as um eixo fundamental de interpretação (SCOTT, 2011).

Questionamos como se dá a produção de cuidado relacionado às experiências reprodutivas em contextos de profundas desigualdades e em cenários amplos em que as "maternidades admiráveis" ( $\mathrm{RICH}$, 1979 apud MATTAR; DINIZ, 2012) se regem por marcadores de classe e raça, numa lógica heteronormativa. 
Nesse sentido, adotamos uma perspectiva interseccional para analisar as trajetórias reprodutivas e a produção de cuidado. Compreendemos as interseccionalidades não apenas como uma somatória de marcadores identitários (de gênero, sexualidades, raça, etnicidade, classe, idade etc.), mas como dinâmicas sociais entrecruzadas (CRENSHAW, 2002; VIVEROSVIGOYA, 2018).

\section{Metodologia}

Os dados analisados são produto de uma pesquisa antropológica sobre as experiências de mulheres em relação à assistência pré-natal prestada pelo SUS na cidade de São Leopoldo (RS) ${ }^{3}$. A investigação qualitativa foi desenvolvida nos anos 2017-2018 em uma Unidade Básica de Saúde (UBS) destinada à saúde materna, localizada no centro da cidade, e em uma Unidade de Saúde da Familia (USF), localizada num bairro periférico - esta última abordada neste texto. Tendo como propósito, segundo Eckert e Rocha (2008, p. 21), "ampliar as possibilidades de reconhecimento das formas de participação e construção da vida social", o método qualitativo de inspiração etnográfica nos ajudou a aguçar o olhar e a escuta atenta. Para a produção dos dados, foram utilizadas as técnicas de entrevista em profundidade e observação participante.

A abordagem biográfica guiou a realização de entrevistas e posterior análise, considerando as narrativas sobre a experiência de um momento particular da vida e as memórias centrais acionadas para reconstituir as trajetórias reprodutivas das entrevistadas. A narrativa é uma das principais formas com as quais as pessoas organizam sua compreensão de mundo (GIBBS, 2009).

A observação participante nos permitiu captar diversas situações ou fenômenos que não são obtidos por meio de questionamentos verbais, uma vez que, observados diretamente em sua própria realidade, demonstram o que existe de mais imponderável e evasivo na vida real. A elaboração do diário de campo foi ligada à observação, por meio dos registros escritos que propiciaram estabelecer a relação entre os eventos observados ou compartilhados, reunindo materiais para analisar práticas, discursos e posições dos sujeitos em campo (BEAUD; WEBER, 2007).

Nosso universo de pesquisa foi constituído em torno de uma USF localizada em bairro periférico da cidade de São Leopoldo. A unidade opera

3 O projeto que originou esta pesquisa foi aprovado pelo Comitê de Ética em Pesquisa da Universidade do Vale do Rio dos Sinos, com Protocolo n`155/2015. 
nesse modelo desde 2010, sendo antecedida por uma UBS. No momento da investigação (março a maio de 2017), atuavam duas equipes, cada uma constituida por: enfermeira, médica de familia vinculada ao Programa Mais Médicos, dentista e agentes comunitários de saúde (majoritariamente mulheres). As duas equipes eram coordenadas pela enfermeira. Ao todo, a USF tinha cerca de oito mil pessoas cadastradas em seu território.

Foram entrevistadas seis mulheres que estavam em diferentes momentos gestacionais, selecionadas a partir de indicações de agentes de saúde por terem histórias diferenciadas. As agentes de saúde se tornaram fundamentais na pesquisa, já que nos apresentavam as histórias das mulheres. $\bigcirc$ percurso com elas até a casa das entrevistadas nos permitiu (re)conhecer o território do ponto de vista de quem o vivencia cotidianamente.

Para guiar a entrevista com as gestantes, utilizou-se um roteiro com questões abertas que estimulassem relatos de vivências e percepções sobre gestação e maternidade, e sobre assistência à saúde. Foram realizadas observações na sala de espera (com conversas informais com as gestantes) e nos atendimentos da enfermeira coordenadora de uma das equipes, que percebemos ter vínculo de longa data com muitas das usuárias.

Para a análise das narrativas biográficas, seguimos a proposta de Jovchelovitch e Bauer (2002), com foco no material indexado (quem fezo que, quando, onde e por que) e não indexado (toda forma de uma generalizada "sabedoria de vida"), para analisar o ordenamento dos acontecimentos para cada indivíduo (trajetórias) e as opiniões, os conceitos e as teorias gerais; para posterior agrupamento e comparação das trajetórias individuais e identificação de trajetórias coletivas. Foram integrados também os dados produzidos na observação e na conversa informal com a equipe de saúde, particularmente com as agentes comunitárias. Cabe destacar que os nomes das entrevistadas foram substituídos por nomes fantasia para preservar o anonimato das participantes.

\section{Resultados e Discussão}

\section{Trajetórias reprodutivas na interseccionalidade de gênero, classe e raça}

território onde residem as entrevistadas e onde se localiza a USF se caracteriza por sua população majoritariamente de baixa renda e escolaridade, em um município onde os habitantes são predominantemente brancos(as) (83,2\%, conforme o Censo de 2010), mas, quando analisamos 
os bairros periféricos da cidade, esse percentual se modifica, tendo maior concentração de residentes negros(as) (INSTITUTO BRASILEIRO DE GEOGRAFIA E ESTATÍSTICA, 2010).

As mulheres entrevistadas estavam na faixa etária entre 16 e 35 anos, e sua escolaridade correspondia em grande parte ao ensino fundamental incompleto - apenas uma delas havia concluído o ensino médio e era agente de saúde. As outras cinco estavam desempregadas e/ou se definiram como "do lar". A mais jovem estava na primeira gestação, enquanto as demais já tinham um ou dois filhos. Quatro delas se autoidentificaram como pretas ou negras e duas como brancas.

Se considerarmos a faixa etária em que ocorreu a primeira gestação de cada uma das entrevistadas, teremos um recorte que varia entre os 13 e 21 anos, sendo que algumas gestações podem ser entendidas como uma experiência juvenil de "aprendizagem e experimentação da sexualidade com parceiro", como apontam Heilborn et al. (2002, p. 16). É o caso de Joana, mulher negra de 20 anos que teve seu primeiro filho aos 13 . Ela conta sobre como aconteceu sua primeira gravidez:

Foi um susto, na verdade nunca passou na minha cabeça que eu estava grávida. Eu descobri assim, a minha tia morava conosco, e a gente sempre ficava menstruada junto, e aconteceu que para ela vinha e, para mim, nunca vinha. E ela começou a achar aquilo meio estranho. Daí ela me perguntou: "tu estás tendo relação?". Porque na cabeça dos meus pais não. Daí eu: "sim". Daí ela: "mas vocês estão se cuidando?", dai eu disse: "às vezes sim, às vezes não, né?". Dai ela disse para mim: "eu não sei se tu estás grávida". Dai eu: "não, bem capaz que eu estou grávida". Dai ela: "vamos fazer um exame médico, daí, se tu estiver, tu vai falar com a tua mãe". Dai ela foi comigo, a gente fez e deu positivo. Foi um susto, nossa! Eu chorei muito, não sabia se chorava de alegria ou de preocupação. Mas foi tranquilo, a mãe e o pai até que foram bem tranquilos, eles me entenderam e me ajudaram e, claro, veio o sermão, mas foi tranquilo. Já o Roberto [gravidez atual] não, faz um ano que eu estava tentando engravidar, porque eu queria dar um irmão para o João, para ele não ficar muito sozinho, e eu engravidei. Tive um aborto espontâneo, dai depois eu consegui engravidar de novo. (Joana).

Depois de descobrir a primeira gravidez, Joana continuou morando na casa dos pais junto com os irmãos e seu companheiro, que foi morar com eles porque o casal não tinha condições de pagar um aluguel (ela trabalhava na indústria calçadista, mas estava desempregada, e o companheiro trabaIhava na construção civil). 
Já Márcia, 16 anos, negra, pela primeira vez grávida, morava com a mãe, que trabalhava de diarista, e a irmã, que estava prestes a casar e se mudar. Ela referiu ter abandonado os estudos porque não conseguia mais estudar no turno da noite, pois era quando sentia mais cansaço. Dentre as entrevistadas, foi a que apresentou a condição socioeconômica mais vulnerável, morando na beira do arroio, numa casa precária de madeira, onde dividia o único quarto com a mãe e a irmã. Ela falou sobre o pai da bebê:

A gente namorava antes, escondido, dai a gente tinha terminado. E daí, quatro dias depois, eu descobri que eu estava grávida. Na verdade, foi a minha mãe, a menstruação dela vinha, a minha vinha primeiro e a dela vinha depois, dai ela desconfiou. Aí eu fui no médico. No começo eu fiquei com bastante medo por causa da gravidez, mas daí, depois que a minha mãe descobriu e meu pai descobriu, parece que eu fiquei mais calma. (Márcia).

Em ambos os casos a descoberta da gravidez formou parte de uma sociabilidade feminina, um compartilhar experiências e conhecimentos do/sobre o corpo entre mulheres próximas. Também, destaca-se a família como principal rede de apoio após a descoberta da gravidez, sendo um espaço de acolhida, cuidado e manutenção socioeconômica.

Entre as entrevistadas, foram as mulheres negras as que gestaram mais jovens e de forma "não planejada", tal como elas referiram. Essas situações coadunam com Leal et al. (2005), que, em estudo realizado no Rio de Janeiro, observaram a ocorrência de contínua situação de desigualdade entre mulheres brancas e negras em diversas categorias, apontando que existia maior concentração de gestantes adolescentes entre as mulheres negras do que entre as brancas, assim como entre as de menor escolaridade. No período da adolescência, essas mulheres se encontram em posição de menor poder de negociação de práticas sexuais seguras, além de não terem reconhecida a legitimidade de seu exercício sexual por parte dos pais e dos profissionais (TAQUETTE, 2009).

Houve também narrativas de mulheres que estabeleceram uma relação estável com seus companheiros, com a decisão de ter filhos como um projeto do casal. Lúcia, branca, 22 anos, identificou-se como dona de casa. Seu primeiro filho nasceu quando ela tinha 20 anos. Perdeu sua mãe muito jovem, o que influenciou, segundo ela, a decisão de se casar mais cedo. Falando sobre a primeira gravidez: 
Nossa! Nós queríamos ele, a gente sempre falava que queria. Eu achava que ia demorar, tanto que, daí, foi um mês, no outro eu já estava grávida. E a gente demorou sete anos para ter ele, esperando, olhando, a gente casou, a gente queria comprar a casa. Dai eu engravidei, a gente conseguiu comprar a casa, deu tudo junto. (Lúcia).

No caso da segunda gravidez, Lúcia narrou que não foi planejada, que foi uma falha com o preservativo masculino, que era o método de anticoncepção usado. Em outras trajetórias, aparece a segunda gravidez como algo planejado, como uma espécie de "lição aprendida" com a experiência de surpresa da primeira gravidez. Foram os casos de Joana, já citado, e de Brenda, negra, 30 anos. Ela teve seu primeiro filho aos 18 anos com o mesmo companheiro e tinha também um filho adotivo. Referindo-se à segunda gravidez, disse: "foi uma gravidez planejada, assim né, eu tive meu filho muito cedo, os dois, bem cedo. Então a gente decidiu ter mais um agora para, mais tarde, não ficar assim 'eu queria ter tido mais um e agora já está tarde, pela questão da idade"'.

Brenda foi a única que mencionou o uso do dispositivo intrauterino (DIU) e a entrevistada com maior escolaridade e melhor condição social: era a única empregada, e sua ocupação como agente de saúde lhe permitiu acesso a informações e garantia de direitos. Ela referiu que já conhecia o método e perguntou para a ginecologista, mas que não foi oferecido no serviço de saúde. Conforme narrou sobre seu planejamento reprodutivo:

Eu usei DIU nove anos, depois que eu tive o meu primeiro filho. Ai eu retirei para gestar mesmo. Daí o tempo que eu fiquei fazendo os exames pré-concepcionais, fiquei usando comprimido. Deu um período de uns oito, nove meses usando comprimido, depois parei para gestar. (Brenda).

Já as narrativas de não planejamento da gravidez, tanto em relação à segunda quanto à terceira gestação, apareceram vinculadas a falhas na anticoncepção. Foi o caso de Laís, 35 anos, branca, com duas filhas - uma com 17 e outra com um ano e meio -, grávida pela terceira vez. Morava com seu marido, duas filhas e com a neta, que tinha a mesma idade que sua filha menor. Ela mencionou que seu marido trabalhava em outra cidade, estando em casa só aos finais de semana. Narrou que ela e sua filha mais velha cuidavam uma da outra (sendo que sua última gravidez coincidiu com a gravidez da filha) e das duas crianças. Tinha também o apoio do pai de Laís, que morava na frente da sua casa e que é um dos fundadores do bairro. 
Em relação à terceira gravidez, falou que foi "muito de surpresa", estava usando Micronor:

Ele tem um prazo para ser tomado e, quando chegou determinado tempo, tinha que ser trocado e não foi trocado, porque a médica, até então, disse que ficou com, que não queria trocar para não secar o leite. Só que nessa ocasião a minha bebê já estava com um ano e um mês, quando eu fui pra trocar, porque eu estava ficando menstruada duas vezes no mês. Então, porque já não estava mais fazendo efeito, e ela não quis trocar devido ao leite, e foi nessa ocasião que aconteceu essa gestação. (Laís).

Laís desejava uma laqueadura como futura medida anticoncepcional. Além dela, outra entrevistada relatou o mesmo desejo: Regina, 32 anos, negra, gestando o terceiro filho. Sua gestação foi classificada como de alto risco em consequência de uma hérnia que desenvolveu após a cesárea do primeiro filho. Conforme o relato da agente de saúde, Regina sofria violência praticada pelo marido, que era usuário de crack. Ambos estavam desempregados, ela em virtude de estar impossibilitada de trabalhar por ter uma gestação de alto risco. Naquele momento, era beneficiária do Programa Bolsa Família (PBF). A agente de saúde narrou, também, que um apoio importante para Regina e seus filhos era a sogra, que residia na casa ao lado e tentava controlar o uso de crack de seu filho. Além da sogra, a mãe da gestante morava no mesmo bairro, em cuja residência ela passava a maior parte do tempo. As vizinhas se organizaram para realizar um chá de fralda para o bebê. Ressaltamos, assim, a rede de apoio conformada em torno da sua maternidade. Regina contou sobre a gravidez que estava vivenciando naquele momento:

$\mathrm{Na}$ verdade, eu nem podia [engravidar], acho que eu me esqueci de tomar um ou dois comprimidos no máximo. Porque eu não podia engravidar, porque eu tenho tela na barriga e tenho uma hérnia. Eu fiquei sabendo quando estava de dois meses e meio, por aí. Fiz um teste ali no postinho que deu positivo. Aí, no começo, eu me desesperei, em nenhum momento eu pensei, né, em tentar, tanto que eu tentei, estou tentando até agora. E graças a Deus está correndo tudo bem. Pensei que ia ser uma gravidez bem sofrida, mas não, tem sendo tranquila. (Regina).

Tanto nesse caso quanto no de Laís, por motivos diversos de dificuldades econômicas elou de risco de saúde, a narrativa sobre a gravidez não planejada veio com a afirmação de valores em relação à vida do bebê: "está bem tranquilo, porque não tem... Deus me livre! Na verdade, está louco, 
mais um, mas é um bebê, não tem como rejeitar uma coisa assim, não tem, apesar de não ser planejado, mas vai ser amado igual" (Laís). A possibilidade de aborto, embora de maneira velada nas narrativas, se vislumbra como impensável. Entendemos que, além dos valores pessoais, o contexto de criminalização da prática impede que sua possibilidade seja sequer verbalizada tanto pelas mulheres quanto pelos profissionais de saúde.

Ressaltamos que, independentemente de situações por elas avaliadas como de "planejamento" ou de "falhas na anticoncepção", percebemos uma ênfase de responsabilidade feminina para o uso de métodos após a união conjugal heterossexual, em consonância com a atuação da equipe de saúde. Como afirma Scott (2011, p. 30), a partir de pesquisas realizadas na atenção primária de municípios do Nordeste brasileiro: "quem regula o tamanho da prole são elas, mesmo que o uso da contracepção seja uma peça constante nas negociações de relações de poder entre homens e mulheres na comunidade". Entendemos essa situação como uma busca dessas mulheres por autonomia reprodutiva.

Como apontam Brandão e Cabral (2017, p. 2), aprender a gerir a contracepção ao longo da vida sexual e reprodutiva das mulheres faz parte de um processo "com múltiplos níveis e [que] compreende uma série de decisões e lógicas complexas entranhadas em diversos domínios da vida", que envolvem desde projetos, desejos e expectativas pessoais e coletivas até situações de vulnerabilidade relacionadas às condições estruturais em que vivem essas mulheres.

Em relação aos homens, observamos que os companheiros e/ou pais das crianças eram da mesma faixa etária das mulheres entrevistadas. Em alguns casos, os homens assumiam o papel de provedores do lar, sendo diferentes os casos de Brenda, que era empregada (agente de saúde) e transpareceu em sua narrativa uma distribuição mais igualitária dos papeis de provedor(a)/ cuidador(a); de Regina, em que ambos estavam desempregados, entretanto ela recebia o benefício do PBF e também concentrava o papel de cuidadora; e o de Márcia, cuja mãe sustentava a casa.

Os cuidados com os filhos apareceram mais ligados às mulheres, sendo que os homens estavam mais vinculados ao papel de provedores. Alguns acompanhavam as consultas de pré-natal, outros não conseguiam por não serem liberados do trabalho. Como analisam Cortez et al. (2016), em estudo sobre como as representações sociais da paternidade influenciam as práticas dos profissionais da saúde, o trabalho é uma das justificativas 
de ausência dos pais durante a assistência pré-natal, sendo que a atividade empregatícia é um elemento forte que identifica o pai com a imagem do homem provedor. Nesse sentido, a ausência do pai nos serviços de saúde se configura como "justa e compreensivel" para os profissionais, e esse discurso acaba reforçando o enfraquecimento das demandadas pela garantia dos direitos dos pais em instâncias trabalhistas.

Nota-se a seguinte fala de Joana, respondendo sobre como eram distribuídos os cuidados com os bebês na sua família:

\begin{abstract}
$\mathrm{Na}$ [gravidez] do João ele [o companheiro] não foi muito presente, porque ele trabalhava mais, muito mais, e ele era muito novo, ele tinha 16 anos. Então, para ele, aquilo era tudo novo, ele até participava, ia nas ecografias e tal, mas era diferente. Agora, nessa gestação, ele já é mais preocupado, ele já sabe ser pai né, dai é diferente, é mais maduro. [...] Quando o João nasceu, ele foi, ele estava presente, tudo, ele ajudava cuidar. Só que ele tinha muito medo, ele tinha aquele medo de pegar, medo de machucar, qualquer coisa que o João chorava, ele já queria correr pro médico, porque ele achava que aquilo não era normal. Já do Roberto eu acho que não, ele vai estar mais pronto para ser pai. (Joana).
\end{abstract}

Ressaltamos os fragmentos "ele era muito novo" e "ele tinha muito medo", que transmitem uma ideia de fragilidade do homem-pai, expressa, por um lado, na imagem de imaturidade e, por outro, na figura de um jovem que se esforçava para aprender o papel de pai. Lembramos que ela, nessa gravidez, tinha 13 anos, o que pode transparecer um papel de mulher-mãe naturalizado, que talvez não tivesse a oportunidade de ser expresso a partir dos seus medos. Ou seja, diferentemente de seu companheiro, três anos mais velho, Joana parece não ter tido tempo para "ser muito nova" ou "sentir muito medo" da maternidade.

Houve também narrativas de entrevistadas negras em que a maternidade se apresentou como uma vivência "solitária". A reflexão sobre a solidão das mulheres negras nas trajetórias afetivas é abordada por intelectuais como bell hooks (1995) e Ana Cláudia Lemos Pacheco (2013), remetendo a subjetividades e dinâmicas estruturantes das sociedades das Américas, que reatualizam a violência colonial que colocava os corpos femininos negros como "incubadoras para a geração de outros escravos" (HOOKS, 1995, p. 469), e não como mulheres que pudessem ser amadas por seus parceiros homens.

Nota-se que, para as mulheres negras que vivenciam a maternidade em solidão, as situações de desigualdades raciais podem se potencializar. 
Segundo mostram Leal et al. (2005), em estudo realizado com puérperas no estado do Rio de Janeiro, entre as mulheres negras, era menos frequente viver com o pai dos bebês, o que pode indicar algum tipo de falta de apoio (seja nos cuidados com a gestação e com o recém-nascido, seja no suporte emocional, ou econômico). As mulheres negras foram também as que ficaram com o maior percentual de chegadas desacompanhadas na maternidade.

Márcia descobriu sua gestação após poucos dias do final do seu namoro, sendo que não teve mais contato com o ex-namorado depois que contou da gestação. $O$ não exercício da paternidade na rotina da gestação e da maternidade acaba somando mais uma carga à rotina da mulher, em uma função que historicamente é centralizada na figura feminina. No caso dela, mãe assumiu a figura de maior apoio para a gestação.

Outra forma de exercício solitário da maternidade apareceu na trajetória de Regina, tendo as atribuições da maternidade centralizadas em sua figura. Quem conseguia auxiliá-la eram as mulheres da sua familia. Seu companheiro não possuía emprego fixo por conta das condições vinculadas ao uso abusivo de crack (condições talvez não captadas pelo serviço de saúde), e ela estava impossibilitada de trabalhar. Era ela a responsável por prover financeiramente sua casa com o benefício do PBF. Era auxiliada pela sogra, a mãe e suas irmãs, mostrando que se criou uma rede feminina de solidariedade, que buscava dar apoio para o cuidado das crianças, sendo esse auxilio essencial para pessoas pertencentes às camadas mais pobres da população, ainda mais perante as lacunas de investimentos em prestação e assistência sociais pelo setor público (DIAS; AQUINO, 2006).

\section{Saúde reprodutiva e produção de cuidado}

Tal como reconstruímos na pesquisa, o bairro em questão tinha uma história de aproximadamente 40 anos. Foi fruto de uma ocupação de familias que vinham de áreas rurais à procura de emprego e das possibilidades ofertadas por uma cidade. Assim se constituiu a parte mais antiga do bairro, com o protagonismo da associação de moradores, ao demandar a ampliação dos serviços no território. A própria construção da unidade de saúde foi produto dessa demanda. Nos últimos anos, o bairro cresceu com sucessivas ocupações, sendo elas nas áreas mais precárias, próximas ao rio que o circunda. Essas áreas sofrem frequentes alagamentos, sendo que esses moradores 
vivem em situações de maior vulnerabilidade social. Como já mencionado, a USF tinha duas equipes, sendo que uma atendia o núcleo do bairro mais antigo, e a outra, a região de moradores mais recentes, em situação de acentuadas vulnerabilidades, com maior proporção de população negra.

Em relação à equipe que atendia o núcleo fundador do bairro, com a qual tivemos mais contato, os atendimentos de pré-natal pareciam ocorrer tranquilamente, principalmente os considerados de "baixo risco", sendo que a equipe dava conta desses cuidados. Quanto às gestantes classificadas como de "alto risco", o atendimento pré-natal ocorria em ambulatórios especializados, mas as agentes de saúde faziam o elo com a atenção primária. Nas observações na USF, notamos uma presença quase absoluta de gestantes e mães levando seus filhos para atendimento. A presença de homens foi muito reduzida e, quando acontecia, era principalmente de idosos.

Podemos relacionar com o apontado por Scott (2011): as construções de gênero nas equipes de saúde colocam os homens (principalmente jovens) como "ameaça", sendo que a exposição permanente a situações de violência e morte é entendida pelas equipes como de responsabilidade prioritária de outros setores públicos (educação, segurança pública etc.). As atividades da USF não eram atraentes para esse público, que considera as unidades de saúde como "espaços femininos". Em compensação, analisando por geração, os homens idosos passam a frequentar a unidade, principalmente para serem assistidos nas suas condições de saúde enfraquecida, que muitas vezes são produto de uma "biologização do seu sofrimento, manifestada em diabetes, hipertensão e outras patologias adquiridas ao longo da vida" (SCOTT, 2011, p. 34).

Durante o trajeto que fizemos acompanhadas pelas agentes comunitárias para ir até a residência de cada entrevistada, elas aproveitavam esses momentos em que circulavam pelo território para repassar recados da enfermeira, avisando de consultas e retiradas de exames, reforçando a necessidade de pré-natal caso fosse uma gestante, entre outras questões. As agentes de saúde pareciam ter mais oportunidades de acessar as mulheres, seja em casa ou circulando pelo bairro, levando os filhos à escola ou indo ao mercado.

Foi expresso pelas entrevistadas um vínculo estreito com a enfermeira da equipe, já que a conhecem de longa data. Quanto aos médicos e médicas, que nos últimos anos eram alocados pelo Programa Mais Médicos (em sua maioria cubanos/as), foi mencionada a alta rotatividade dos profissionais, o que dificultava a criação de vínculo. Além disso, várias mulheres afirmaram que o fato deles serem médicos generalistas (e não ginecologistas) 
as deixava receosas nos atendimentos de pré-natal. Podemos entender essas expectativas das mulheres dentro de um discurso disseminado de que o "especialista", no caso ginecologista, é o profissional médico mais legitimado e autorizado para o cuidado com os corpos grávidos.

Warmling et al. (2018), em estudo realizado com profissionais de saúde que atuam na atenção primária com o cuidado pré-natal no Sul do Brasil, destacam tensões entre os discursos de medicalização (centrados na prática do médico especialista ginecologista/obstetra) e de humanização (baseados na prática generalista de uma equipe multiprofissional). Esses discursos são produzidos em dispositivos biopolíticos de gestão da vida que levam, em alguns casos, a se contrapor e tencionar a produção de "verdades" sobre os corpos grávidos, mas, em muitos outros, a prática medicalizadora se sobrepõe.

Porém, no nosso campo, foi ressaltado como positivo o protagonismo da enfermeira na assistência, por ser uma profissional "mais próxima das mulheres", sendo valorizada a confiança para perguntar e conversar com as enfermeiras sobre questões que não se animariam em discutir com os médicos. Como Joana expressou:

A médica atende bem, só que ela é mais tranquila, mais calma. Ela fala o que tem para falar, pede o que tem para pedir, olha o que tem para olhar e deu. A enfermeira já não, ela conversa, ela vai medir ele, vai ver o coraçãozinho conversando com ele. Já com a médica, ele foge, é uma briga para ela achar o coração, e com a enfermeira ele fica tranquilo, sabe? Eu gosto mais da consulta com ela, não sei se por ela ter feito o meu pré-natal com o João, eu sinto mais confiança, e ela ter atendido o João até ele ficar grande, né, sempre cuidou dele. Então, quem sabe, é a confiança mesmo, por conhecer a mais tempo. (Joana).

A contracepção e o planejamento reprodutivo foram dois temas de destaque tanto nas falas das gestantes quanto na dos trabalhadores de saúde, pensando amplamente no público que atendem. Como analisa Scott (2011), as mulheres encontram mais ressonância para suas necessidades na esfera da reprodução do que para outras esferas da vida: "[o] controle da reprodução, desejado por ela como meio de administrar e planejar sua vida conjugal e familiar calha perfeitamente com o temor generalizado das camadas médias sobre a reprodução, supostamente desenfreada, dos pobres" (SCOTT, 2011, p. 30).

Durante as observações das consultas de pré-natal realizadas pela enfermeira, ouvimos várias mulheres com demandas de laqueadura e de troca de método contraceptivo. A contracepção apareceu vinculada quase 
exclusivamente ao corpo das mulheres. Houve poucas menções ao uso de preservativo masculino, e não apareceu alusão alguma à vasectomia, por exemplo. Observamos também uma falta de variedade dos métodos anticoncepcionais ofertados na rede de saúde, limitados à pílula, injeção e laqueadura. $\bigcirc$ uso de DIU foi referido apenas pela entrevistada que tinha maior escolaridade e emprego como agente de saúde, não sendo um método sugerido na rede de saúde, como já dito anteriormente.

Esses resultados coadunam com outros estudos sobre métodos anticoncepcionais, por exemplo, Heilborn et al. (2009), que notaram entre mulheres da cidade do Rio de Janeiro que o acesso às laqueaduras, ao DIU e à contracepção de emergência não eram garantidos integralmente pelos serviços de saúde pública.

Gonçalves et al. (2019) analisam dados de estudo transversal de base populacional com mulheres de 20 a 49 anos de São Leopoldo (RS), sobre métodos contraceptivos utilizados e fatores demográficos e socioeconômicos associados. Os autores notam que as mulheres mais jovens, de menor escolaridade e classe econômica mais baixa, apresentaram menor uso de anticoncepcional oral. Já a laqueadura foi mais prevalente entre as de classe econômica mais baixa, na faixa etária de 30 a 39 anos. Os resultados mostraram que existem diferenças persistentes quanto à contracepção, o que pode se relacionar tanto a dificuldades no acesso como a fragilidades das ações em saúde reprodutiva para abarcar as necessidades e preferências das mulheres em situações de maior vulnerabilidade social.

Conforme a Pesquisa Nacional sobre Demografia e Saúde da Criança e da Mulher (PNDS) (BRASIL, 2006), no período entre 1986 a 1996, apontou-se um expressivo aumento no uso de contraceptivos. Contudo nota-se uma importante diferença na escolha dos métodos contraceptivos utilizados: foi observada escolha progressiva pela esterilização feminina. Esse aumento se deu principalmente nas regiões Norte, Nordeste e Centro-Oeste do país, com destaque para o decréscimo de idade das mulheres que realizavam o procedimento. Já nos anos de 1996 a 2006, houve crescimento expressivo no uso de métodos contraceptivos. Apesar do declínio no número de esterilizações femininas, a intervenção segue como método mais utilizado, principalmente entre as mulheres de baixa renda e escolaridade (BRASIL, 2006).

No nosso estudo, percebemos que as mulheres que apresentavam a demanda de laqueadura vivenciavam assimetrias de gênero que as colocavam 
em uma posição de desvantagem (tanto social e econômica quanto por serem vítimas de violência). Eram mulheres que já tiveram experiências anteriores com outros métodos contraceptivos e que decidiram realizar uma laqueadura em conjunto com a profissional de saúde que as acompanhava, mas que tinham sua decisão prejudicada em virtude das limitações do fluxo de atendimento no município.

Em São Leopoldo, existe somente uma equipe multidisciplinar que realiza $o$ atendimento para encaminhar a laqueadura, sediada em ambulatório no centro da cidade. $O$ primeiro atendimento só pode ser agendado via telefone, um fluxo criado em virtude das grandes filas que se formavam durante a madrugada no local para a marcação de consultas. Porém, durante - período da realização da pesquisa, foram presenciadas reclamações do(as) usuário(as) sobre o agendamento, não só para esse atendimento como para as demais especialidades do ambulatório.

Para atendimento pela equipe multidisciplinar que realiza o que a Secretaria Municipal de Saúde nomeia como "planejamento familiar", a espera inicial podia passar de 60 dias. A enfermeira da USF relatou que essa demora acabava fazendo que algumas mulheres não conseguissem comparecer no prazo marcado, o que levava à necessidade de realizar uma nova consulta na USF e reiniciar o fluxo. Isso retardava ainda mais o procedimento, quando não a desistência, e abria brechas para que essas mulheres engravidassem novamente sem esse desejo.

É interessante notar que as entrevistadas que engravidaram mais jovens relataram não ter contato com serviços de saúde em relação à saúde sexual e reprodutiva. Márcia mencionou que, até ficar grávida, nunca havia passado por um atendimento ginecológico ou de aconselhamento sobre métodos contraceptivos, que declarou também nunca ter usado. Joana passou a utilizar a injeção anticoncepcional após o parto do seu primeiro filho, quando começou a frequentar mais a unidade de saúde. Percebemos que ambas frequentavam o serviço quando crianças, levadas pelas mães quando havia necessidade. Entretanto se afastaram ao entrar na adolescência, voltando a ser visualizadas pelo serviço quando foram levadas pela família para fazer o teste de gravidez e descobriram a gestação. Notamos a existência de uma situação limiar na qual essas jovens entram quando já não são identificadas dentro de um público historicamente prioritário para os serviços de saúde, como são as crianças. $\bigcirc$ que percebemos na USF pesquisada é que as adolescentes parecem voltar a "serem vistas" pelas equipes quando se 
tornam gestantes. A partir de então, são captadas pelas agentes de saúde na rua, nas suas casas, e entram na rotina de atendimento da equipe.

Coadunamos com Robles (2015), que ressalta que as regulações e normatividades agindo no corpo grávido vêm entrelaçadas àquelas que procuram a captação rápida para a construção de um "projeto de criança" entre as mulheres jovens, na suposição de gestações imprevistas. Isso nos ajuda a entender a invisibilidade das jovens para as equipes de saúde até o momento de se tornarem gestantes e, aí sim, serem rapidamente captadas pelo serviço, que só as visibilizava quando crianças.

No caso de Márcia, como já referido, em sua primeira gestação, aos 16 anos, morava com sua mãe e expressou que continuaria com ela, já que sustentava a casa com seu trabalho de diarista. Em relação ao reconhecimento da filha pelo pai, Márcia declarou não querer registrá-la com o nome do pai, já que eles não voltaram a conversar depois que ele soube da gravidez. Porém Márcia expressou não haver problema caso ele e a criança se conheçam: "eu posso apresentar ela para o pai dela, o pai dela também tem direito de vir atrás dela". É interessante notar a cena que aconteceu no dia da entrevista entre Márcia e a agente de saúde, quando esta insistiu para que a adolescente registrasse sua filha com o nome do pai. Quando terminamos a entrevista, quase imediatamente a agente de saúde passou a falar da importância do uso de contraceptivo após o parto, para não engravidar novamente, e reiterou que Márcia "registrasse corretamente sua filha", para poder "cobrar a pensão do pai da bebê", já que ela não trabalhava e também havia abandonado a escola.

Quando saímos da casa de Márcia, a agente expressou sua preocupação com ela e a situação em que sua família vivia. Pois, no entendimento da agente de saúde, a mãe de Márcia a superprotege em função da gestação, e a irmã acabou antecipando sua saída de casa por se sentir excluída. O salário da irmã fará falta na casa, ainda mais com as despesas de um recém-nascido e com Márcia sem previsão de ter trabalho ou da pensão ser paga pelo pai da bebê. Vemos o comprometimento da agente com a situação passada pela família, mas, ao mesmo tempo, uma tentativa de regulação de como a jovem deveria lidar com a parentalidade.

Em relação à assistência ao parto das entrevistadas que já tinham filhos, foram narradas situações de violência sofridas na maternidade pública da cidade. Ressaltamos o caso de Regina por ser a vivência mais "marcada no corpo" e que expressa uma série de descasos disseminados pela rede de 
saúde, para além do atendimento no hospital. A entrevistada relata suas experiências de assistência das duas primeiras gestações:

[na primeira gestação] eu peguei uma médica que não era obstetra, era médica da família aqui no postinho. Ela falou que a placenta tinha virado, por isso que eu não ia ganhar normal, mas lá no hospital me falaram: "não, moça, tu deve ter confundido, porque a placenta não tem como virar, a placenta não vira, o que vira é o nenê". Daí até hoje eu não sei por que eu não ganho normal, mas desde o primeiro... O segundo foi porque eu não tinha nenhum músculo na barriga, a primeira gestação me arrebentou toda a musculatura que eu tenho na barriga. Abriu no meio, tanto que botaram a tela no lugar do músculo, daí não tinha como empurrar mesmo, que os dez dedos de dilatação já tinha. Eu ganhei o nenê, eu fiquei uma semana de depressão, porque o meu couro da barriga que tinha esticado, ele caiu tudo no chão assim, no chão não, nas minhas pernas né, mas caiu tudo assim, era horrivel, descascava, foi assim, horrivel mesmo. (Regina).

Desde falhas de comunicação com a médica de familia, que provocaram incertezas sobre a indicação de cesariana, até a pressuposição de negligências na assistência pré-natal e na própria cirurgia deixaram marcas em seu corpo que afetaram profundamente sua vida e sua autoestima. Notamos também uma ausência de cuidado por parte da rede de saúde no puerpério, uma invisibilidade desse corpo feminino negro sofrendo. Ainda reforçando o processo de invisibilização:

Quando eu ganhei o último agora, o doutor [ginecologista que acompanhou o pré-natal] me deu um papel e tudo, pedindo que ele [obstetra do hospital] fizesse a laqueadura, e ele falou que não podia, porque eu tinha só dois filhos, e que a tela, não tinha nada a ver eu engravidar com a tela, porque a tela esticava como músculo. Agora eu levei mais um xingão do médico, que falaram que tem tudo a ver sim, que eu não podia ter engravidado, que é alto risco mesmo, principalmente na hora de ganhar. (Regina).

Regina, seu corpo e sua história se tornaram invisiveis no meio de protocolos e procedimentos de rotina, nos devaneios entre os médicos da atenção primária e da atenção hospitalar, ainda sendo culpabilizada pelo fato de engravidar novamente.

Leal et al. (2017) apontam, como indicador de iniquidade racial, que mulheres negras sofreram menos intervenções obstétricas no parto do que as brancas, evidenciando um "menor cuidado" denotado na não realização de intervenções necessárias para suas condições de saúde. Outro indicador de 
iniquidade racial analisado pelas autoras foi em relação ao percentual de mulheres negras que receberam anestesia local quando submetidas à episiotomia, que se mostrou inferior ao de mulheres brancas. A menor oferta de anestésicos no parto vaginal para as mulheres negras já tinha sido constatada no estudo de Leal et al. (2005) em maternidades do Rio de Janeiro. Apontam-se, no caso de Regina, complexas situações de violência obstétrica, potencializadas por sua condição de mulher negra e pobre, relacionadas com dispositivos de racismo institucional disseminados na rede de saúde (LÓPEZ, 2012).

\section{Considerações finais}

Como resultados do estudo destacam-se trajetórias reprodutivas com diferenças expressivas entre as mulheres entrevistadas, ao considerar os efeitos da violência estrutural que conjuga desigualdades de gênero, classe, raça e idade. Observamos trajetórias diferenciadas conforme o pertencimento racial dessas mulheres, sendo que as violências aparecem de maneira mais acentuada sobre os corpos femininos negros.

As narrativas das mulheres apresentaram importantes marcas relacionadas às dimensões de classe e raça em sua vida reprodutiva quando considerado o acesso a métodos contraceptivos e orientações a este respeito. Quando saem da infância para a adolescência, essas mulheres ficam num limiar onde não são mais vistas como prioritárias para os serviços de saúde. Isso acaba refletindo de forma decisiva em suas vivências, sendo um dos fatores importantes para experiências de gestação na adolescência, como as relatadas no estudo. Apontamos de maneira propositiva que o hiato existente entre a atenção em saúde de jovens e o cuidado direcionado aos seus corpos grávidos poderia ser atenuado com ações focadas no conhecimento de seus próprios corpos mediante abordagem de questões relativas ao prazer, à fertilidade e ao autocuidado com vistas ao empoderamento dessas adolescentes. Nesse sentido, a atenção deslocaria efetivamente o foco da saúde reprodutiva para a saúde da mulher, possibilitando de forma mais eficaz seus direitos sexuais e reprodutivos.

Diante das assimetrias que atravessam a vida dessas mulheres e permeiam suas trajetórias de saúde reprodutiva, suas agências foram uma importante característica que se apresentou em meio aos contextos adversos, seja no esforço em buscar garantir sua autonomia reprodutiva; seja na 
ativação de redes de apoio, principalmente entre as mulheres da familia, quando se confrontaram com maternidades em solidão.

No que diz respeito à produção de cuidado, observarmos um vínculo duradouro (principalmente da enfermeira e das agentes de saúde) e um engajamento da equipe da USF nas realidades vivenciadas pelas mulheres. Notamos que o pré-natal aciona dispositivos de regulação dos corpos, reproduzindo certas noções de mulher-mãe-pobre que centraliza as responsabilidades reprodutivas e de cuidado dos filhos, sobrepondo estas noções às desigualdades de gênero, classe, raça, idade, que acabam sendo invisibilizadas ou naturalizadas. Essas desigualdades apareceram (re)produzidas e potencializadas no conjunto da rede de saúde, com negligências e violações de direitos reprodutivos (como são os casos do ineficiente acesso à laqueadura e a outros métodos anticoncepcionais e das violências sofridas durante a assistência ao parto). Cabe refletir sobre o fato de que o cuidado em saúde direcionado a estas mulheres é produzido majoritariamente por mulheres que, em um lugar de privilégio, como trabalhadoras da saúde, acabam por reproduzir assimetrias e reforçar as desigualdades de gênero que se aprofundam quando se sobrepõem à classe e à raça.

Entretanto o pré-natal apareceu como espaço de aberturas, encontros e, muitas vezes, perplexidades dos(as) trabalhadores(as) por não poder abarcar de maneira mais efetiva o conjunto de desigualdades e violências que afetam a vida dessas mulheres. Esses cenários exigem políticas públicas intersetoriais mais encorpadas para gerar caminhos de equidade, assim como deslocamentos do foco meramente reprodutivo, para abarcar a saúde e a vida das mulheres na garantia ampla de direitos.

\section{Referências}

BEAUD, S.; WEBER, F. Guia para a pesquisa de campo: produzir e analisar dados etnográficos. Petrópolis: Vozes, 2007.

BRANDÃO, E.; CABRAL, C. Da gravidez imprevista à contracepção: aportes para um debate. Cadernos de Saúde Pública, Rio de Janeiro, v. 33, n. 2, p. e00211216, 2017.

BRASIL. Pesquisa Nacional de Demografia e Saúde da Criança e da Mulher. Brasilia, DF: Ministério da Saúde, 2006. 
CONNELL, R. Gênero em termos reais. São Paulo: nVersos, 2016.

CORTEZ, M. B. et al. Profissionais de saúde e o (não)atendimento ao homempai: análises em representações sociais. Psicologia em Estudo, Maringá, v. 21, n. 1, p. 53-63, 2016.

CRENSHAW, K. Documento para o encontro de especialistas em aspectos da discriminação racial relativos ao gênero. Estudos Feministas, Florianópolis, v. 10, n. 1, p. 171-188, 2002.

DIAS, A. B.; AQUINO, E. M. L. Maternidade e paternidade na adolescência: algumas constatações em três cidades do Brasil. Cadernos de Saúde Pública, Rio de Janeiro, v. 22, n. 7, p. 1447-1458, 2006.

ECKERT, C.; ROCHA, A. L. C. Etnografia: saberes e práticas. Iluminuras, Porto Alegre, v. 9, n. 21, p. 1-23, 2008.

GIBBS, G. Análise de dados qualitativos. Porto Alegre: Artmed, 2009.

GONÇALVES, T. R. et al. Desigualdades sociais no uso de contraceptivos em mulheres adultas no Sul do Brasil. Revista de Saúde Pública, São Paulo, v. 53, n. 28, p. 1-12, 2019.

HEILBORN, M. L. et al. Aproximações socioantropológicas sobre a gravidez na adolescência. Horizontes Antropológicos, Porto Alegre, v. 8, n. 17, p. 13-44, 2002.

HEILBORN, M. L. et al. Assistência em contracepção e planejamento reprodutivo na perspectiva de usuárias de três unidades do Sistema Único de Saúde no estado do Rio de Janeiro, Brasil. Cadernos de Saúde Pública, Rio de Janeiro, v. 25, n. 2, p. S269-S278, 2009.

HOOKS, B. Intelectuais negras. Revista Estudos Feministas, Florianópolis, n. 2, p. 464-478, 1995.

INSTITUTO BRASILEIRO DE GEOGRAFIA E ESTATÍstICA. Censo demográfico 2010: características da população e dos domicílios. Rio de Janeiro, 2010. 
JOVCHELOVITCH, S.; BAUER, M. W. Entrevista narrativa. In: BAUER, M. W.; GASKELL, G. Pesquisa qualitativa com texto, imagem e som: um manual prático. Petrópolis: Vozes, 2002.

LEAL, M. C. et al. Desigualdades raciais, sociodemográficas e na assistência ao pré-natal e ao parto, 1999-2001. Revista de Saúde Pública, São Paulo, v. 39, n. 1, p. 100-107, 2005.

LEAL, M. C. et al. A cor da dor: iniquidades raciais na atenção pré-natal e ao parto no Brasil. Cadernos de Saúde Pública, Rio de Janeiro, v. 33, n. 1, p. e00078816, 2017.

LÓPEZ, L. C. O conceito de racismo institucional: aplicações no campo da saúde. Interface, Botucatu, v. 16, n. 40, p. 121-134, 2012.

MATTAR, L. D.; DINIZ, C. S. G. Hierarquias reprodutivas: maternidade e desigualdades no exercício de direitos humanos pelas mulheres. Interface, Botucatu, v. 16, n. 40, p. 107-19, 2012.

MERHY, E. E. Em busca do tempo perdido: a micropolítica do trabalho vivo em ato, em saúde. In: FRANCO, T. E; MERHY, E. E. Trabalho, produção do cuidado e subjetividade em saúde. São Paulo: Hucitec, 2013. p. 19-67.

PACHECO, A. C. L. Mulher negra: afetividade e solidão. Salvador: EDUFBA, 2013.

ROBLES, A. F. Regulações do corpo e da parentalidade durante o pré-natal em mulheres de camadas populares. Civitas: Revista de Ciências Sociais, Porto Alegre, v. 15, n. 2, p. 190-213, 2015.

SCOTT, P. As famílias que os programas de saúde pública constroem no Brasil. In: NASCIMENTO, P.; RIOS, L. F. (org.). Gênero, saúde e práticas profissionais. Recife: Editora UFPE, 2011. p. 13-50.

TAQUETTE, S. R. O paradoxo da moral sexual na adolescência e as DST/Aids. In: TAQUETTE, S. R. Aids e juventude: gênero, classe e raça. Rio de Janeiro: Eduerj, 2009. p. 135-154.

VIELLAS, E. F. et al. Assistência pré-natal no Brasil. Cadernos de Saúde Pública, Rio de Janeiro, v. 30, n. 1, p. S85-S100, 2014. 
VIVEROS-VIGOYA, M. A cor das masculinidades. Experiências interseccionais e práticas de poder na Nossa América. Rio de Janeiro: Papéis Selvagens, 2018.

WARMLING, M. C. et al. Práticas sociais de medicalização \& humanização no cuidado de mulheres na gestação. Cadernos de Saúde Pública, Rio de Janeiro, v. 34, n. 4, p. 1-11. 2018.

Recebido em outubro de 2019.

Aprovado em março de 2020. 